\title{
Long term follow-up of laser myopia surgery
}

\author{
Gracia Castro-Luna ${ }^{1}$, Hazem Alaskar ${ }^{2}$, Antonio Pérez-Rueda ${ }^{3}$ Diana Jimenez-Rodriguez ${ }^{4}$ \\ 1 Department of Nursing, Phisyotherapy and Medicine. University of Almería; graciacl@ual.es \\ 2 Hospital Universitario Poniente. Almería. Spain; Hazemalaskar@yahoo.es \\ 3 Hospital Universitario Torrecárdenas. Almería. Spain; a.perezrueda.oft@gmail.com \\ 4 Department of Nursing, Phisyotherapy and Medicine. University of Almería; djr239@ual.es \\ * Correspondence: graciacl@ual.es Tel.: (+34 659490770)
}

\begin{abstract}
Background Refractive surgery is an increasingly popular procedure to decrease spectacle or contact lens dependency. The two most commonly used surgical techniques to correct myopia is Photorefractive keratectomy (PRK) and Femtosecond- Lasik (FS-LASIK)There are few publications that gathers such a long term follow up of both surgical techniques (2) Methods It has been performed a retrospective non-randomized study 509 PRK eyes and 310 FS-LASIK surgeries were followed for 10 years for the treatment of myopia and compound myopic astigmatism. Patients were followed up three months, one year, 2 years, 5 and 10 years. The safety index of both procedures was defined as a quotient between the postoperative BCVA (Best Corrected Visual Acuity) and the preoperative BCVA. The predictability is calculated as difference between the expected spherical equivalent and the achieved spherical equivalent. The efficacy index was calculated as a quotient between postoperative UCVA divided by the preoperative BCVA (3) Results. The results were: a safety index higher than $100 \%$ (109\%) and an efficacy index of $82.4 \%$ after 10 years of PRK surgery in both groups. FS-LASIK was the safest surgery after 10 years and the most efficacy technique although in this case there were no statistically significant differences (4) Conclusions. All these data demonstrated better indexes for FS-LASIK
\end{abstract}

Keywords: laser excimer; myopia surgery; long term; Femto-LASIK; PRK

\section{Introduction}

Refractive surgery is an increasingly popular procedure to decrease spectacle or contact lens dependency. The two most commonly used surgical techniques to correct myopia are photorefractive keratectomy (PRK) plus mitomycin C application [1-11] and Femtosecond- Lasik (FS-LASIK) [12-15]. The number of FS-LASIK procedures has increased and surpasses the number of PRK procedures owing to faster visual recovery, less pain and more excellent ametropic range capability [16-18]. PRK is still performed today, especially in corneas with superficial scarring, epithelial dystrophies or recurrent erosions, in thin corneas, after penetrating keratoplasty and for refractive retreatments. Continued analysis of the safety and efficacy of these procedures is highly relevant [18] and necessary to informed consent and evidence-based clinical practice in refractive surgery. We conducted a retrospective non-randomized analysis of the outcomes to determine the safety, predictability and efficacy of performing PRK or FS-LASIK for 10 years. 


\section{Methods}

We performed a retrospective study of 509 eyes treated through PRK and 310 FS-LASIK. Data came from the medical records of patients operated in the INVISION ophthalmological hospital (Almería, Spain). The spherical equivalent refraction was between -0.5 and -33 diopters. Preoperative requirements were: myopia and compound myopic astigmatism, no contact lenses for two weeks before surgery, stable refraction for at least six months before surgery. The corneal pachymetry was enough to leave a residual bed of at least $250 \mu \mathrm{m}$ and not topographical signs of keratoconus. Surgery exclusion criteria were: evidence of ectasia or suspected keratoconus evidenced in corneal topography estimated postoperative corneal thickness less than $350 \mu \mathrm{m}$, eye disease or active systemic disease affecting corneal healing, pregnancy and lactation. Visual acuity was measured with a standard Snellen 38 acuity chart at 6 meters and expressed in a decimal fraction. Uncorrected Visual Acuity (UCVA) and Best Corrected Visual Acuity (BCVA) were evaluated in all patients with the autorefractometer (ARK-700, Nidek, Japan). Also, the following tests were performed: biomicroscopic examination (BQ 900, Haag Strait, Swiss), IOP (Noncontact tonometer, Reichert Inc., Buffalo, NY, USA), fundus examination, corneal topography (CM02, CSO, Oftaltech, Italy), C.E. count (SP-2000, Topcon, Japan) and size of the pupil (Pupilographer, Florence, Italy). Patients hadn't another ocular disease.

The ablation procedure was performed through Esiris Excimer laser (Schwind Eyetech-solution $\mathrm{GmbH}, \mathrm{Kleinostheim,} \mathrm{Germany)} \mathrm{in} \mathrm{all} \mathrm{the} \mathrm{procedures} \mathrm{in} \mathrm{both} \mathrm{groups.} \mathrm{In} \mathrm{FL} \mathrm{group} \mathrm{the} \mathrm{corneal} \mathrm{flap}$ was obtained through Intralase ${ }^{\circledR}$ femtosecond laser (Intralase ${ }^{\circledR}$ femtosecond laser Abbott Laboratories Lake Bluff, Illinois, United States) before the ablation phase, taking data of depth of ablation, the thickness of the programmed flap, sphere and cylinder programmed in the laser. Patients were followed up 3 months, 1 year, 2 years, 5 and 10 years gathering data on the UCVA, BCVA, postoperative subjective refraction, topographic cylinder, and pachymetry. The safety index of both procedures was defined as a quotient of the postoperative BSCVA divided by the preoperative BCVA [11-13]. We defined a procedure as safe if this quotient is equal or greater than 1. The predictability was calculated as the difference between the expected spherical equivalent and the achieved spherical. The percentage of eyes with a spherical equivalent of $\pm 1 \mathrm{dp}$ (diopter) after surgery was analyzed. The efficacy index was calculated as a quotient of the postoperative UCVA divided by the preoperative BCVA [11-14]. The conditions for re-treating a patient included some of the following three parameters: a shift from emmetropy greater than $1.00 \mathrm{D}^{\prime \prime}$, UCVA of 20/40 $<0.5$ decimal fraction scale) or less and patient dissatisfaction with the visual result. Undercorrection was defined as residual refraction of a spherical equivalent of $-1.00 \mathrm{D}$ or higher at the postoperative visit at three months. Regression was defined as a shift from emmetropy greater than $0.5 \mathrm{D}$ between follow-up visits. in patients who have not undergone a retreatment

\section{Data Analysis}

Statistical analysis was performed using SPSS 22.0 for Windows software (SPSS Inc., Chicago, $\mathrm{IL})$. Values are presented as means \pm standard deviation (sd); the level of significance was set at $\alpha=$ 0.05 (2 tailed). Normality was verified with the test of Kolmogorov-Smirnov. Visual outcomes were compared using a non-parametric Wilcoxon test (two independent samples) and Kruskal-Wallis test. 


\section{Results}

Table 1 shows the demographic characteristics of both groups. No statistically significant differences were reported between the PRK group and FS-LASIK group. PRK patients were 123 men and 131 women with an average age of 31.6 \pm 9.34. FS-LASIK patients were 68 men and 87 women with an average age of $33.6 \pm 10.07$.

Table 1 Preoperative characteristics.

\begin{tabular}{lcc}
\hline & \multicolumn{1}{c}{ PRK } & FS-LASIK \\
\hline Number of eyes & 509 & 310 \\
Sphere* $_{\text {Cylinder* }}^{*}$ & $-7.07(1.24)$ & $-7.30(1.12)$ \\
Axial Lenght & $-1.33(1.07)$ & $-1.52(1.11)$ \\
Pachymetry $^{* * *}$ & $25.71(1.68)$ & $27.72(2.02)$ \\
\hline
\end{tabular}

* diopters ${ }^{* *} \mathrm{mms}^{* * *}$ microns

The mean preoperative spherical equivalent refraction was $-7.18 \pm 1.13$ for the PRK eyes and $-7.19 \pm 1.06$ for the FS-LASIK eyes. Preoperative BCVA mean was $0.73 \pm 0.20$ for PRK eyes and $0.74 \pm$ 0.21 for FS-LASIK eyes.The number of retreatments was 47 out of a total of 310 cases $(15.16 \%)$ in FS-LASIK patients. PRK retreatments were 90 out of a total of 509 eyes $(17.68 \%)$. The reasons for retreatment were uncorrected refractive errors in all cases of FS-LASIK surgery. In the patients who underwent retreatment after PRK surgery, the reasons were a regression of refraction in $35 \%$ and uncorrected refractive errors in the rest. The regression was probably due to the non-application of mitomycin C in cases of PRK below $6 \mathrm{dp}$ (diopters) as reflected in the protocols of surgery at the beginning of the realization of this database. No long-term complications have been reported in PRK and FS-LASIK patients. Spherical equivalent in PRK group was $-0.84 \pm 1.01$ at 3 months, $-0.72 \pm 0.91$ at 1 years, $-0.69 \pm 0.90$ at 2 years, $-0.80 \pm 1.19$ at 5 years and $-1.22 \pm 1.54$ at 10 years after surgery. Spherical equivalent in FS-LASIK group was $-1.66 \pm 1.64$ at 3 months, $-1.09 \pm 1.22$ at 1 year, $-0.82 \pm$ 1.14 at 2 years, $-0.79 \pm 0.83$ at 5 years and $-0.92 \pm 0.93$ at10 years after surgery.

\subsection{Predictability Index}

Predictability was calculated for each follow-up period, including all eyes that were retreated, to assess the outcome of the techniques. The predictability index was $\pm 1 \mathrm{dp}$ in $80,9 \%$ of the cases at 3 months, $87.3 \%$ at 1 year, $88.2 \%$ at 2 years, $85.4 \%$ at 5 years, and finally $73.4 \%$ at 10 years after PRK. In FS-LASIK, the predictability index was $57,1 \%$ at 3 months, $80 \%$ at 1 year, $93 \%$ at 2 years, $75 \% 5$ years and $76.2 \% 10$ years after surgery (Table 2 ) 
Table 3: Predictability Index

PREDICTABILITY \pm 1DP $(\%)$

\begin{tabular}{cccccc}
\hline & 3 months & 1 year & 2 years & 5 years & 10 years \\
\hline PRK & $80.9 \%$ & $87.3 \%$ & $88.2 \%$ & $85.4 \%$ & $73.4 \%$ \\
FS-LASIK & $57.1 \%$ & $80.0 \%$ & $93.8 \%$ & $75.0 \%$ & $76.2 \%$ \\
\hline
\end{tabular}

PREDICTABILITY \pm 2DP $(\%)$

\begin{tabular}{cccccc}
\hline & 3 months & 1 year & 2 years & 5 years & 10 years \\
\hline PRK & $93.5 \%$ & $95.8 \%$ & $95.2 \%$ & $95.1 \%$ & $89.6 \%$ \\
FS-LASIK & $85.7 \%$ & $95.0 \%$ & $100.0 \%$ & $95.0 \%$ & $85.7 \%$ \\
\hline
\end{tabular}

\subsection{Safety Index}

The safety index at 3 months, 1 year, 2 years, 5 years and 10 years after surgery are shown in Table 4. The preoperative BCVA was $0.73 \pm 0,20$ in the PRK group and $0.74 \pm 0.21$ in FS-LASIK group. For all patients undergoing PRK surgery BCVA was $0.62 \pm 0,18$ at 3 months, $0.70 \pm 0.20$ at 1 year, $0.72 \pm 0.18$ at 2 years, $0.77 \pm 0.19$ at 5 years, and $0.79 \pm 0.20$ at 10 years. For all patients undergoing FS-LASIK surgery BCVA was $0.74 \pm 0.21$ at 3 months, $0.75 \pm 0.21$, at 1 year, $0.78 \pm 0.21$ at 2 years, 0.80 \pm 0.20 at 5 years, and $0.82 \pm 0.23$ at 10 years after. Table 4 shows the differences in safety indexes between re-treated and no-retreated patients. Values higher than 1 was due to the postoperative BCVA was better than the preoperative BCVA in a great number of patients with both surgeries. There are statistically significant differences in safety indices between patients undergoing FS-LASIK surgery and those undergoing PRK. Safety indices were higher in all patients undergoing FS-LASIK surgery to PRK in both cases: patients who underwent retreatment and those who did not undergo retreatment.

Table 4: Safety Index

\section{RETREATMENTS}

\begin{tabular}{llllll}
\hline & 3 months & 1 year & 2 years & 5 years & 10 years \\
\hline PRK & $0.88 \pm 0.28$ & $0.96 \pm 0.27$ & $1.00 \pm 0.26$ & $1.08 \pm 0.28$ & $1.11 \pm 0.34$ \\
FS-LASIK & $1.04 \pm 0.35$ & $1.13 \pm 0.39$ & $1.18 \pm 0.37$ & $1.10 \pm 0.42$ & $1.21 \pm 0.47$ \\
p-value & $<0.01^{*}$ & $<0.01^{*}$ & $<0.01^{*}$ & 0.299 & $0.023^{*}$ \\
\hline
\end{tabular}

${ }^{*} \mathrm{p}<0.05$ significance 
NO-RETREATMENTS

\begin{tabular}{llllll}
\hline & 3 months & 1 year & 2 years & 5 years & 10 years \\
\hline PRK & $0.92 \pm 0.29$ & $1.04 \pm 0.31$ & $1.05 \pm 0.33$ & $1.10 \pm 0.30$ & $1.12 \pm 0.34$ \\
FS-LASIK & $1.09 \pm 0.32$ & $1.15 \pm 0.36$ & $1.21 \pm 0.48$ & $1.19 \pm 0.43$ & $1.23 \pm 0.49$
\end{tabular}

Safety $10 \mathrm{y}$

p-value

$<0.01^{*}$

$<0.01^{*}$

$<0.01^{*}$

$<0.01^{*}$

$<0.01^{*}$

${ }^{*} \mathrm{p}<0.05$ significance 
FS-LASIK PRK

\begin{tabular}{|c|c|c|c|c|c|}
\hline & mean & $\mathrm{sd}$ & mean & sd & p-value \\
\hline Less than $-10 \mathrm{dp}$ & 1.27 & 0.57 & 1.23 & 0.52 & $<0.05^{*}$ \\
\hline-10 to $-6 \mathrm{dp}$ & 1.19 & 0.34 & 1.12 & 0.33 & \\
\hline More than $-6 \mathrm{dp}$ & 1.27 & 0.85 & 1.08 & 0.28 & \\
\hline \multicolumn{6}{|l|}{ Safety 5y } \\
\hline & \multicolumn{2}{|c|}{ FS-LASIK } & \multicolumn{2}{|c|}{ PRK } & \\
\hline & mean & $\mathrm{sd}$ & mean & sd & p-value \\
\hline Less than $-10 \mathrm{dp}$ & 1.22 & 0.49 & 1.16 & 0.64 & $<0.05^{*}$ \\
\hline-10 to $-6 \mathrm{dp}$ & 1.14 & 0.31 & 1.08 & 0.29 & \\
\hline More than $-6 \mathrm{dp}$ & 2.12 & 2.61 & 1.07 & 0.24 & \\
\hline \multicolumn{6}{|l|}{ Safety $2 y$} \\
\hline & \multicolumn{2}{|c|}{ FS-LASIK } & \multicolumn{2}{|c|}{ PRK } & \\
\hline & mean & sd & mean & $s d$ & $\mathrm{p}$-value \\
\hline Less than $-10 \mathrm{dp}$ & 1.55 & 3.67 & 1.21 & 0.56 & 0.1 \\
\hline-10 to $-6 \mathrm{dp}$ & 1.12 & 0.32 & 1.02 & 0.25 & \\
\hline More than $-6 \mathrm{dp}$ & 1.79 & 3.11 & 1.05 & 0.94 & \\
\hline \multicolumn{6}{|l|}{ Safety $1 y$} \\
\hline & \multicolumn{2}{|c|}{ FS-LASIK } & \multicolumn{2}{|c|}{ PRK } & \\
\hline & mean & sd & mean & sd & $\mathrm{p}$-value \\
\hline Less than $-10 d p$ & 1.19 & 0.4 & 1.16 & 0.53 & 0.06 \\
\hline-10 to $-6 \mathrm{dp}$ & 1.06 & 0.32 & 0.98 & 0.25 & \\
\hline More than $-6 \mathrm{dp}$ & 1.01 & 0.24 & 0.98 & 0.23 & \\
\hline \multicolumn{6}{|l|}{ Safety $3 \mathrm{~m}$} \\
\hline & \multicolumn{2}{|r|}{ FS-LASIK } & \multicolumn{3}{|c|}{ PRK } \\
\hline & mean & $\mathrm{sd}$ & mean & sd & $\mathrm{p}$-value \\
\hline Less than $-10 \mathrm{dp}$ & 1.11 & 0.36 & 1 & 0.49 & $<0.01^{*}$ \\
\hline-10 to $-6 \mathrm{dp}$ & 1.04 & 0.28 & 0.87 & 0.24 & \\
\hline More than $-6 \mathrm{dp}$ & 1.19 & 0.84 & 0.89 & 0.25 & \\
\hline
\end{tabular}

Table 5 shows the safety indexes according to the surgical technique and the preoperative sphere. In all cases, the safety is higher than 1 (means that postoperative BCVA is almost the same as preoperative BCVA) except in patients operated by PRK at 3 months and one year after surgery. There are statistically significant differences between FS-LASIK and PRK. FS-LASIK are the safest tecnique

Table 5: Safety index according to preoperative sphere and surgical technique

\subsection{Efficacy Index}


Defined as the quotient of the postoperative UCVA divided by the preoperative BCVA after surgery. UCVA was $0.58 \pm 0.23$ at 3months, $0.61 \pm 0.23$ at 1year, $0.65 \pm 0.24$ at 2 years, $0.61 \pm 0.27$ at 5

Efficacy $10 \mathrm{y}$ years and

$0.49 \pm 0.22$ at 10 years for all patients undergoing PRK surgery. UCVA were $0.63 \pm 0.24$ at 3 months, $0.68 \pm 0.25$ at 1 year, $0.67 \pm 0.23$ at 2 years, $0.68 \pm 0.25$ at 5 years, and $0.59 \pm 0.27$ at 10 years for all patients undergoing FS-LASIK surgery. The efficacy indexes were higher with a statistical difference for FS-LASIK surgery at 3 months, 1 year and 2 years follow-up period. At 5 and 10 years of follow-up, these differences were not maintained, and the efficacy results were equal but with a slight difference in favour of FS-LASIK surgery. (Table 6)

Table 6: Efficacy Index

\section{RETREATMENTS}

\begin{tabular}{llllll}
\hline & 3 months & 1 year & 2 years & 5 years & 10 years \\
\hline PRK & $0.56 \pm 0.29$ & $0.73 \pm 0.30$ & $0.79 \pm 0.32$ & $0.87 \pm 0.31$ & $0.83 \pm 0.38$ \\
FS-LASIK & $0.59 \pm 0.35$ & $0.86 \pm 0.43$ & $0.92 \pm 0.39$ & $0.91 \pm 0.44$ & $0.88 \pm 0.49$ \\
p value & 0.711 & $0.0323^{*}$ & $0.0263^{*}$ & 0.7854 & 0.5324 \\
\hline
\end{tabular}

* $\mathrm{p}<0.05$ significance

\section{NO-RETREATMENTS}

\begin{tabular}{llllll}
\hline & 3 months & 1 year & 2 years & 5 years & 10 years \\
\hline PRK & $0.83 \pm 0.29$ & $0.92 \pm 0.30$ & $0.92 \pm 0.26$ & $0.91 \pm 0.32$ & $0.86 \pm 0.44$ \\
FS-LASIK & $0.93 \pm 0.33$ & $0.98 \pm 0.33$ & $1.02 \pm 0.51$ & $0.94 \pm 0.38$ & $0.88 \pm 0.49$ \\
p value & $<0,01^{*}$ & $0.0281^{*}$ & $0.0259^{*}$ & 0.6251 & 0.9935 \\
\hline
\end{tabular}

${ }^{*} \mathrm{p}<0.05$ significance 
FS-LASIK

PRK

Table

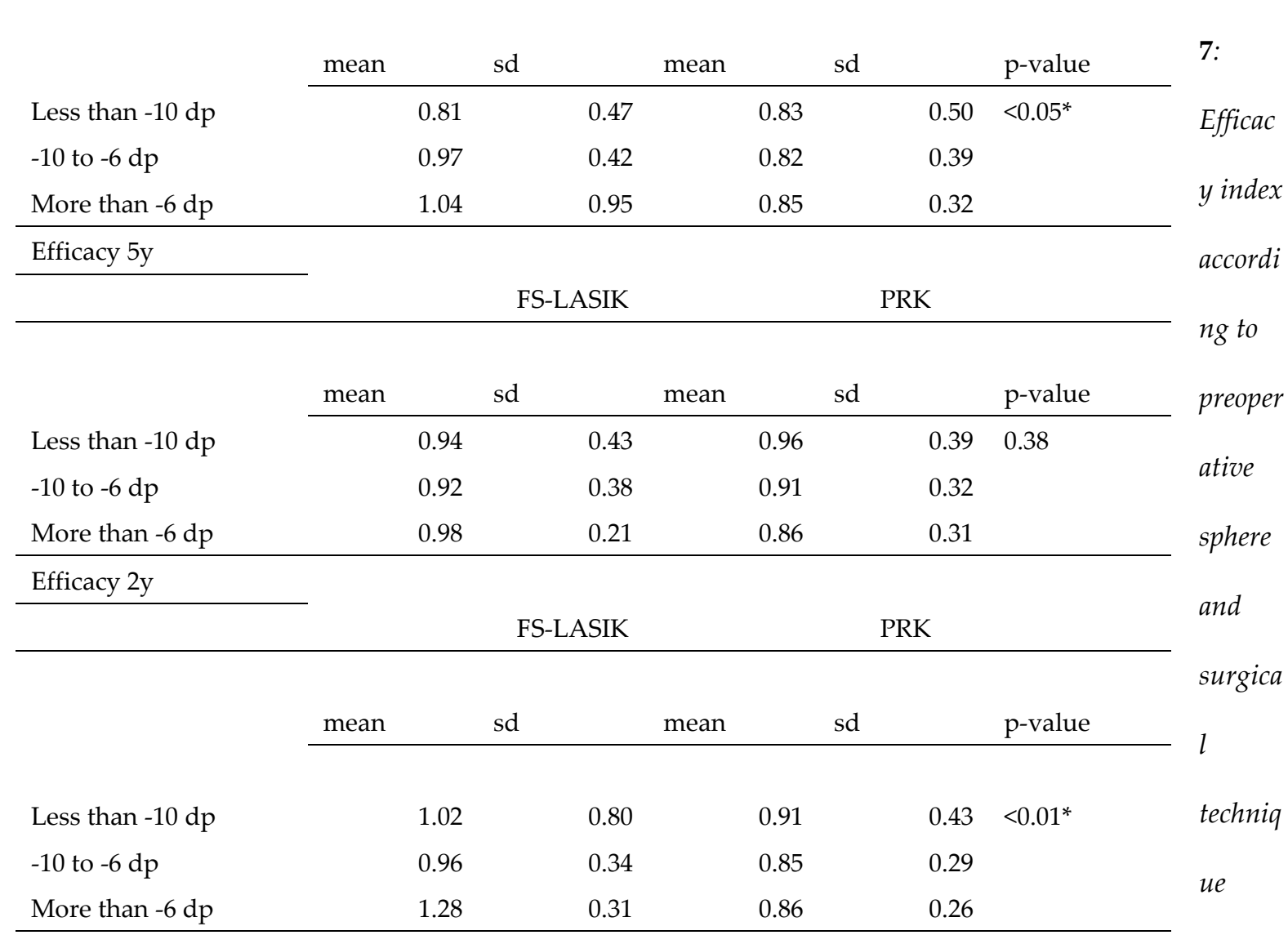

Efficacy $1 y$

FS-LASIK

PRK

mean

sd

mean

sd

p-value

\begin{tabular}{lllll} 
& & & \\
Less than $-10 \mathrm{dp}$ & 0.97 & 0.39 & 0.90 & $0.48<0.01^{*}$ \\
-10 to $-6 \mathrm{dp}$ & 0.91 & 0.33 & 0.81 & 0.31 \\
More than -6 dp & 1.09 & 0.93 & 0.83 & 0.26 \\
\hline
\end{tabular}

Efficacy $3 \mathrm{~m}$

PRK

\begin{tabular}{lrrrrr} 
& mean & sd & mean & sd & p-value \\
\cline { 2 - 6 } & & & & & \\
Less than -10 dp & 0.84 & 0.40 & 0.71 & $0.46<0.05^{*}$ \\
-10 to -6 dp & 0.82 & 0.32 & 0.69 & 0.30 & \\
More than -6 dp & 1.08 & 0.88 & 0.72 & 0.31 \\
\hline
\end{tabular}


Table 7 shows the efficiency indices according to the surgical technique and the preoperative sphere. There are statistically significant differences between FS-LASIK and PRK. FS-LASIK was the most effective technique. However, at 5 and 10 years after surgery in the myopic range of -6 to -10 diopters and greater than -10 diopters, the efficacy rates are similar for both techniques.

\section{Discussion}

Excimer laser refractive surgery has become a popular technique. The new excimer laser equipment with new ablation profiles and faster eye-tracker has improved the results of refractive surgery. The widespread use of the femtosecond laser to make the flap has been one of the most significant advances in improving the safety and reliability of the procedure compared to the mechanical microkeratome [14-16]. PRK is currently used in patients with suspected pathological topographies or cases of thin corneas. The use of mitomycin $C$ on the stromal bed after ablation has allowed PRK surgeries in patients with high myopia by avoiding the appearance of haze in the postoperative period [8-9,17]. Less postoperative pain, fast visual recovery and minimal incidence of haze has made FS-LASIK the preferred procedure in refractive surgery [18].

We performed a retrospective non-randomized study of 509 PRK eyes and 310 FS-LASIK eyes. The patients were followed for ten years. There are few publications that gather such a long term follow up of both surgical techniques. This study has demonstrated good behaviour of both long-term techniques for all preoperative spheres. The predictability of PRK surgery was higher than FS-LASIK surgery, which would suggest that its lower level of safety and efficacy compared to FS-LASIK surgery could be due to this regression of the refractive defect. The high number of retreatments has led us to consider the efficacy and safety indices divided into two groups of patients, one that underwent retreatment and one that didn't [19]. The results have shown a statistically significant increase in safety in patients operated with FS-LASIK compared to those operated with PRK in both groups in retreatment and non-retreatment group. By separating patient groups between those who underwent treatment and those who did not, there are differences statistically significant in the safety indices throughout the follow-up period in both groups in favour of the FS-LASIK technique except in the group of those who underwent treatment at 5 years of follow-up whose differences are not statistically significant. The efficacy rates were higher with a statistical difference for FS-LASIK surgery at 3 months, 1 year and 2 years follow-up period. At 5 and 
10 years of follow-up, these differences were not maintained, and the efficacy results were similar, but with a slight difference in favour of FS-LASIK surgery. Authors such as Sajjadi et al. [20], and Al Mahmoud et al. [21] reported the same results but with shorter follow-up time. Hashemi et al. [22] after 6 months of follow-up reports an efficacy index of $1.01 \pm 0.05$ for PRK and $1.01 \pm 0.14$ after FS-LASIK higher than our results. Finally, in a recent meta-analysis of refractive surgery techniques conducted by Wen et al. [23], FS-LASIK surgery achieved the best indices of safety and efficacy although not statistically significant differences [24].

\section{Conclussions}

All the results suggest that FS-LASIK is a technique with a safety and efficacy superior to PRK. PRK surgery should be used in cases of the thin corneal thickness or topographic alterations that contraindicate FS-LASIK.

Ethical approval: All procedures performed in studies involving human participants were by the ethical standards of the institutional and national research committee and with the 1964 Helsinki declaration and its later amendments or comparable ethical standards.Approval by Ethics Committee Torrecárdenas University Hospital. Reference number is 19/2019.

Informed consent: Informed consent was obtained from all individual participants included in the study.

Author Contributions: Conceptualization, G.C.L. and D.J.R; methodology, G.C.L.; formal analysis, G.C.L; investigation, G.C.L and H.A; data curation, G.C.L; writing-original draft preparation, G.C.L and H.A; writing-review and editing, G.C.1.;. All authors have read and agreed to the published version of the manuscript

Funding: This research received no external funding

Conflicts of Interest: The authors declare no conflict of interest

\section{References}

1. Carones F, Vigo L, Scandola E \& Vacchini L (2002): Evaluation of the prophylactic use of mitomycin-C to inhibit haze formation after photorefractive keratectomy. J Cataract Refract Surg 28: 2088-2095.

2. Bedei A, Marabotti A, Giannecchini I, Ferretti C, Montagnani M, Martinucci C \& Barabesi L (2006): Photorefractive keratectomy in high myopic defects with or without intraoperative Mitomycin C: 1-year results. Eur J Ophthalmol 16: 229-234.

3. Shalaby A, Kaye GB \& Gimbel HV (2009): Mitomycin C in photorefractive keratectomy. J Refract Surg 25: 93-97.

4. Teus MA, de Benito-Llopis L \& Alio J.L. (2009): Mitomycin C in corneal refractive surgery. Surv Ophthalmol 54: 487-502.

5. Hofmeister EM, Bishop FM, Kaupp SE \&Schallhorn SC (2013): Randomized dose-response analysis of mitomycin- $C$ to prevent haze after photorefractive keratectomy for high myopia. J Cataract Refract Surg 39:1358-1365.

6. Torricelli AA, Parede TR, Netto MV, Crestana FP, Bechara S.J. Intraocular straylight before and after low myopic photorefractive keratectomy with and without mitomycin C. Arq Bras Oftalmol. 2016 Apr;79(2):88-91. doi: 10.5935/0004-2749.20160027.PMID: 27224070. 
7. Hashemi M, Amiri MA, Tabatabaee M, Ayatollahi A. Pak J. The results of photorefractive keratectomy with Mitomycin-C in myopia correction after 5 years. Med Sci. 2016 Jan-Feb;32(1):225-8. doi: 10.12669/pjms.321.8576.PMID: 27022380.

8. Sy ME, Zhang L, Yeroushalmi A, Huang D, Hamilton DR Effect of mitomycin-C on the variance in refractive outcomes after photorefractive keratectomy. J Cataract Refract Surg. 2014 Dec;40(12):1980-4. doi: 10.1016/j.jcrs.2014.02.048. Epub 2014 Oct 8. PMID 25305150.

9. Sia RK, Ryan DS, Edwards JD, Stutzman RD, Bower KS. The U.S. Army Surface Ablation Study: comparison of PRK, MMC-PRK, and LASEK in moderate to high myopia. J Refract Surg. 2014 Apr;30(4):256-64. doi: 10.3928/1081597X-20140320-04.PMID: 24702577.

10. Shojaei A, Ramezanzadeh M, Soleyman-Jahi S, Almasi-Nasrabadi M, Rezazadeh P, Eslani M. J. Short-time mitomycin-C application during photorefractive keratectomy in patients with low myopia. Cataract Refract Surg. 2013 Feb;39(2):197-203. doi: 10.1016/j.jcrs.2012.09.016. Epub 2012 Nov 23. PMID: 23183351.

11. Zare M, Feizi S, Azimzadeh A, Esfandiari H. Effect of photorefractive keratectomy with mitomycin-C on corneal biomechanical features. Curr Eye Res. 2012 Jun;37(6):457-62. doi: 10.3109/02713683.2012.660594.PMID: 22577762.

12. Hashmani S, Hashmani N, Rajani H, Ramesh P, Soomro JA, Hussain Shah SR, Kumar J, Mahmood Shah SM. Comparison of visual acuity, refractive outcomes, and satisfaction between LASIK performed with a microkeratome and a Femto laser. Clin Ophthalmol. 2017 May 23; 11:1009-1014. doi: 10.2147/OPTH.S137451. eCollection 2017. PubMed PMID: 28579752; PubMed Central PMCID: PMC5449167.

13. Tabacaru B, Stanca HT. One-year refractive outcomes of Femtosecond-LASIK in mild, moderate and high myopia. Rom J Ophthalmol. 2017 Jan-Mar;61(1):23-31. PubMed PMID: 29450367; PubMed Central PMCID: PMC5710049.

14. Vega-Estrada A, Alió JL, Arba Mosquera S, Moreno LJ. Corneal higher-order aberrations after LASIK for high myopia with a fast repetition rate excimer laser, optimized ablation profile, and femtosecond laser-assisted flap. J Refract Surg. 2012 Oct;28(10):689-96. doi: 10.3928/1081597X-20120921-0.

15. Ehlke GL, Krueger RR. Laser Vision Correction in Treating Myopia. Asia Pac J Ophthalmol (Phila). 2016 Nov/Dec;5(6):434-437. Review.PMID:27898448.

16. Xia L-K, Yu J, Chai G-R, Wang D, Li Y. Comparison of the femtosecond laser and mechanical microkeratome for flap cutting in LASIK. International Journal of Ophthalmology. 2015;8(4):784-790. doi:10.3980 /j.issn .2222-3959.2015.04.25.

17. Mohammadi SF, Ashrafi E, Norouzi N, Abdolahinia T, Mir-AbouTalebi M, Jabbarvand M.J Effects of mitomycin-C on the tear film, corneal biomechanics, and surface irregularity in mild to moderate myopic surface ablation: preliminary results.J Cataract Refract Surg. 2014 Jun;40(6):937-42. doi: 10.1016/j.jcrs.2013.10.043. Epub 2014 Apr 13. PMID:24726159.

18. Hashmani N, Hashmani S, Ramesh P, et al. A Comparison of Visual Outcomes and Patient Satisfaction Between Photorefractive Keratectomy and Femtosecond Laser-Assisted in Situ Keratomileusis. Muacevic A, Adler JR, eds. Cureus. 2017;9(9): e1641. doi:10.7759/cureus.1641. 
19. Mohammadi S-F, Nabovati P, Mirzajani A, Ashrafi E, Vakilian B. Risk factors of regression and under-correction in photorefractive keratectomy: a case-control study. International Journal of Ophthalmology. 2015;8(5):933-937. doi:10.3980 / j.issn .2222-3959.2015.05.14.

20. Sajjadi V, Ghoreishi M, Jafarzadehpour E. Refractive and Aberration Outcomes after Customized Photorefractive Keratectomy in Comparison with Customized Femtosecond Laser. Medical Hypothesis, Discovery and Innovation in Ophthalmology. 2015;4(4):136-141.

21. AlMahmoud T, Munger R, Jackson WB. Effects of advanced surface ablations and IntraLase femtosecond LASIK on higher-order aberrations and visual acuity outcome. Saudi J Ophthalmol.2011;25:275-80. PMID: 23960936.

22. Hashemi H, Miraftab M, Ghaffari R, Asgari S.Femtosecond-Assisted LASIK Versus PRK: Comparison of 6-Month Visual Acuity and Quality Outcome for High Myopia. Eye Contact Lens. 2016 Nov;42(6):354-357.

23. Wen D, McAlinden C, Flitcroft I, Tu R, Wang Q, Alió J, Marshall J, Huang Y, Song B, Hu L, et al. Postoperative Efficacy, Predictability, Safety, and Visual Quality of Laser Corneal Refractive Surgery: A Network Meta-analysis. Am J Ophthalmol. 2017 Jun; 178:65-78. Epub 2017.

24. Vega-Estrada A, Alio JL. Femtosecond-assisted laser in situ keratomileusis for high myopia correction: Long-term follow-up outcomes. Eur J Ophthalmol. 2019 Mar 8:1120672119834478. doi: 10.1177/1120672119834478. [Epub ahead of print] 